\title{
IMPLICATIONS OF CLIMATE CHANGE ON CROP WATER REQUIREMENTS IN HUKKERI TALUK OF BELAGAVI DISTRICT, KARNATAKA, INDIA
}

\author{
Manasa H. G. ${ }^{1}$, Anand V. Shivapur ${ }^{2}$ \\ ${ }^{I}$ M.Tech. Student, Department of Water and Land Management, Visvesvaraya Technological University, Belagavi, \\ India, \\ manasa.vagi@gmail.com \\ ${ }^{2}$ Professor, Department of Water and Land Management, Visvesvaraya Technological University, Belagavi, India, \\ av_shivapur@rediffmail.com
}

\begin{abstract}
Global climate change is a serious trouble in this present century. An increase in the temperature may promote detrimental effects on the available water. In majority of the countries agriculture is the vast sector in the use of water, including India. The objective of this study is to verify the effects of climate change on water requirements of the major crops grown in Hukkeri taluk of Belagavi district using CROPWAT 8.0 software. For this analysis, daily climatic data like minimum temperature, maximum temperature, humidity, sunshine hours, wind speed, and rainfall for Base line scenario is used in addition to Crop data and soil data. Future climate data are collected for A1B scenario (2021-2050) using PRECIS model which was established on the basis of Hadley Centre's Regional Climate Modeling System (HadCM3). Reference evapotranspiration (ETo) of the crop was calculated using monthly average of climaticl data with the help of CROPWAT 8.0 software and then crop water requirement is calculated. The crop water requirement value obtained for Base line conditions is compared with AlB scenario and adaptation strategies for AlB climate change scenarios are suggested.
\end{abstract}

Keywords: Climate Change, Crop Water Requirement, CROPWAT, PRECIS.

\section{INTRODUCTION}

Climate change may be referred to as variation in mean weather patterns or in other words time change of weather throughout the long haul normal conditions (i.e., higher or lesser major climatic events). Changes in Climate occurred due to various influencing factors such as changes in solar radiations accepted by earth, biotic processes, tectonic plates, and volcanic eruptions. Some human actions are also recognized as important reasons for current climate change, and noted as "global warming".

Climate changes have possible impacations on the hydrological cycle and more so on the accessible water resources and the water required for agriculture. Therefore there is concentration about climate change effects on agricultural yield. Along with industrialization, the increased utilization of fossil fuels leads to much increment in environmental grouping of primary gases. As for the relations between the climate system and hydrological cycle, each change on the climate may impact on factors such as temperature, precipitation, stream flow, ground water level, runoff and this prompts change in water necessities of crops in agriculture and also domestic and industrial demand of water.

Agriculture is one of the sectors that is most affected by continual climate change. The wide range of articles on this topic demonstrates that damages occurred due to climate change can be applicable to both livestock and cropping activities. Literally climate change may effect on different agricultural dimensions like, causing losses in profitability, productivity, and employment. Due to the imbalance of crop production, food prices, induced changes in markets and supply chain infrastructure, climate change clearly threatens the food security.

The term 'crop water requirement' means the "total amount of water required by the crop and the way in which it requires water from the time of planted up to the time it is harvested". Water necessity will fluctuate with the yield and in addition with the spot, as such, diverse harvest will have distinctive water prerequisites; dependent upon the varieties in kind of soil, atmospheres, valuable precipitation and technique for development and so on. The Irrigation requirement (IR) indicates the difference between the Evapotranspiration of the crop under ideal conditions (ETc) and the Effective Rainfall (ER) contributions during the same time period and it is expressed in $\mathrm{mm}$. Irrigation requirement typically indicates the excess quantity of the water that has to be supplied through irrigation in order to guarantee to the crop optimal growing conditions. In this study CROPWAT in combination with PRECIS is used for the estimation of crop water requirements (CWR) and comparison of CWR are made for Base line (present condition) with A1B scenario (future projected scenario). 


\section{CROPWAT}

It is an irrigation planning and management model developed by the Water and Land Development Department of FAO. The most common version now is CROPWAT 8.0 Edition (2009), which was developed under the assistance from the University of Southampton and Institute of Irrigation and Development Studies. CROPWAT is a computer program which uses the FAO Penman-Monteith procedure for the estimation of reference crop evapotranspiration $\left(E T_{\mathrm{O}}\right)$, crop evapotranspiration $\left(E T_{\mathrm{C}}\right)$ and irrigation scheduling (FAO 1992). Major input parameters of the program are agricultural meteorological data, crop growth data, and soil data, which include (1) meteorological data: highest temperature, lowest temperature, sunshine, relative humidity, wind speed and rainfall; (2) crop growth data: growing days, crop factor, depth of root system and (3) soil data: extreme infiltration rate, extreme rooting depth, gross available water and primary soil moisture depletion.

\section{STUDY AREA}

The area taken for the study is Hukkeri taluk of Belagavi district, Karnataka, which is situated about $50 \mathrm{~km}$ from Belagavi on north direction. Hukkeri is located at latitude of $16.23^{\circ} \mathrm{N}$ and longitude of $74.6^{\circ} \mathrm{E}$. It has an average elevation of $631 \mathrm{~m}(2,070 \mathrm{ft})$ and total geographical area of 99140 ha. Annual rainfall of Hukkeri taluk varies from 619.4 to 1303.2 $\mathrm{mm}$. Around $61 \%$ of precipitation is obtained in kharif season. The agro climatic zone of the study area is northern transitional zone (K8). It comes under hot semi-arid ecological region. In the study area at Hidkal, a dam has been built over River Ghataprabha, with the Krishna River basin. It is also called as Raja Lakhamgouda dam. It is one of the greatest dams in Belgavi disrict. Majority of the crops grown in the hukkeri taluk are fed through this Hidkal dam. The most extreme storage capacity of the dam is about 51 tmcft. Hidkal dam was finished in 1977, with the motivation behind creating hydroelectric force and also supplying drinking water and supplying water for irrigation in encompassing regions. Around 22 villages in the encompassing zones and around 13,500 hector of agricultural area uses the water from dam for irrigation.

Major types of soils exists in the study area are red sandy loam and black clay soil in equal proportions.

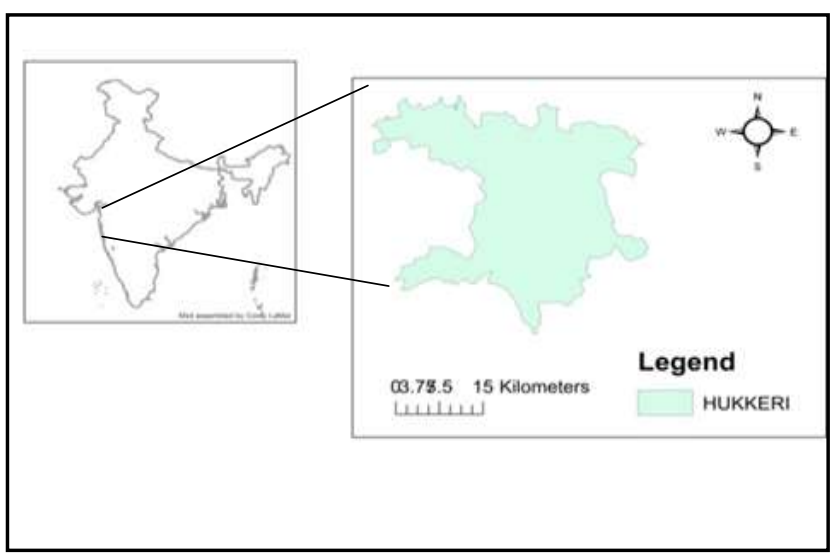

Fig-1: Location Map of Hukkeri taluk in India.

\section{METHODOLOGY}

In this study daily climatic data for Base line condition were collected from Indian Meteorological Department, Bangalore and PRECIS based on HadRM3 data is collected for A1B scenario. Crop details are collected from Agricultural Department, Belagavi. CROPWAT model was used for the evaluation of Reference Evapotranspiration and Crop water requirements for the major crops in the study area.

\subsection{Estimation of Reference Crop}

Evapotranspiration:

"The rate of evapotranspiration from a Reference crop that to not short of water is termed as Reference evapotranspiration $\left(E T_{O}\right)$ ". The conception of $E T_{O}$ is to determine the evaporative requirement of the atmosphere not depends on type of crop, development of crop and management practices. The only factors affecting $E T_{O}$ are weather parameters i.e., temperature, wind speed, relative humidity and sunshine hours. The FAO Penman- Monteith equation is suggested as the single method for determining $E T_{O}$.

$$
E T_{o}(\mathrm{~mm} / \text { day })=\frac{0.408 \Delta\left(R_{n}-G\right)+\gamma \frac{900}{T+273} U_{2}\left(e_{s}-e_{a}\right)}{\Delta+\gamma\left(1+0.34 U_{2}\right)}
$$

Where,

$\Delta=$ slope of the saturation vapor pressure temperature relationship $(\mathrm{KPa} / \mathrm{C})$

$T=$ mean air temperature $\left({ }^{\circ} \mathrm{C}\right)$

$\gamma=$ psychrometric constant $\left(\mathrm{KPa} /{ }^{\circ} \mathrm{C}\right)$

$e_{s}=$ mean saturation vapor pressure $(\mathrm{KPa})$

$R_{n}=$ net radiation on the crop surface $\left(\mathrm{MJ} / \mathrm{m}^{2} /\right.$ day $)$

$G=$ soil heat flux $\left(\mathrm{MJ} / \mathrm{m}^{2} /\right.$ day $)$

$U_{2}=$ measured wind speed at 2 meter height $(\mathrm{m} / \mathrm{s})$

$e_{a}=$ actual vapour pressure $(\mathrm{KPa})$

\subsection{Determination of Crop Water Requirement:}

The word crop water requirement is described as the "amount of water that is essential to balance the evapotranspiration depletion from the cropped field". "However the values for crop evapotranspiration and water requirement of crops are similar, water requirement of crop mentions the amount of water that required to be supplied, while crop evapotranspiration mentions the amount of water that is dissipated during evapotranspiration" [Allen et al. 1998]. The crop ET $\left(E T_{c}\right)$ was determined by u s ing FAO Penman-Monteith equation (FAO, 1998),

$E T_{C}=K_{C} \times E T_{O}$

Where,

$E T_{\mathrm{C}}=$ actual evapotranspiration by the crop ( $\mathrm{mm} /$ day), $E T_{\mathrm{O}}=$ reference crop evapotranspiration ( $\mathrm{mm} /$ day); $K_{\mathrm{C}}=$ crop coefficient at a certain growth stage. 
To estimate the crop water requirement, three decades namely decade I, II, and III and four stages of growth out of the seven crop growth stages were considered viz., initial stage, development stage, mid-season and harvesting stage.

\section{RESULTS AND DISCUSSIONS}

The average climatic data of 10 years is used for the determination of reference evapotranspiration $\left(E T_{o}\right)$ for Base line condition and the value varied from $3.2 \mathrm{~mm} /$ day in December to $5.28 \mathrm{~mm} /$ day in May. The reference evapotranspiration is calculated for future scenario i.e., for A1B, dividing it into 3 decades 2021-30, 2031-40 and 204150. $\mathrm{ET}_{\mathrm{o}}$ values varied from $2.43 \mathrm{~mm} /$ day in July to 6.15 $\mathrm{mm} /$ day in May for the decade 2021-30, from $2.22 \mathrm{~mm} /$ day in July to $6.91 \mathrm{~mm} /$ day in May for 2031-40 and from 2.17 $\mathrm{mm} /$ day in July to $7.51 \mathrm{~mm} /$ day in May.

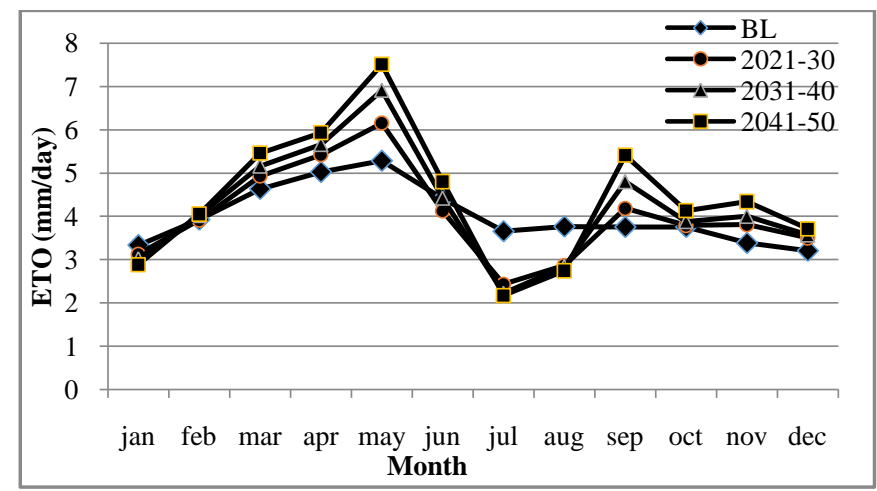

Chart-1: ETO comparison between BL and A1B scenario

During the Kharif season, the rainfall obtained in the months is very high as compared to other season and hence the effective rainfall(ER) is also more. The crop water requirements for kharif crops are shown in table 1.

Jowar (Kharif): The CWR for the crop in BL condition is higher than in the three decades of A1B scenario. For Base line condition from the mid-season to beginning of the harvesting season(late season) of the crop there is rise in temperature and wind speed therefore in that duration the effective rainfall is less than the CWR and so requires lesser water for irrigation, whereas for all the three decades the ER is sufficient to compensate ET losses. Hence there is no water requirement for irrigation.

Maize (Kharif): The CWR for the crop in BL condition is higher than in the three decades of A1B scenario i.e., 2021$30,2031-40$ and 2041-50. In base line condition from the end of the development stage to mid of the harvesting season of the crop growth period the ER is less than the $\mathrm{CWR}$ and so requires lesser water for irrigation. For the case of decades 2031-40 1nd 2041-50 during the harvesting season of the growth period the crop will get less ER than the CWR, therefore additional IR is needed. But in the case of decade 2021-30 the ER is sufficient to compensate ET losses making no requirement for irrigation.

Groundnut (Kharif): The CWR for the crop is higher for BL condition as compared to the period 2021-30. But in the period 2031-40 and 2041-50, it is $3.3 \%$ and $11.64 \%$ more than the CWR in BL. For the three decades in the initial and development stage of the crop growth period the CWR is less than ER, hence no IR for the crop. Whereas during mid to harvesting season of crop growth stage as the CWR is more than the ER, additional IR is needed to compensate ET losses in the decades 2021-30,2031-40 and 2041-50 i.e., $25.5 \%, 50.3 \%$ and $79.1 \%$ more than that for BL condition respectively.

Soybean (Kharif): The CWR for the crop is more for BL condition as compared to the periods 2021-30 and 2031-40 and it is $0.5 \%$ more in the period 2041-50 than in BL. For the three decades in the initial, development and beginning of the mid-season stage of the crop growth period the CWR is less than ER, hence no water is required for irrigation. Whereas during end of mid-season to harvesting season of crop growth stage as the CWR is more than the ER, additional IR is needed to compensate ET losses in the decades 2021-30,2031-40 and 2041-50 i.e., 91.4\%, 79.3\% and $55.7 \%$ less than that for BL condition respectively.

Cotton (Kharif): The CWR for the crop is more for BL condition as compared to the periods 2021-30 and 2031-40 and it is $2.4 \%$ more in the period 2041-50 than in BL. For the three decades in the initial, development and beginning of the mid-season stage of the crop growth period the CWR is less than ER, therefore no IR is needed. Whereas during end of mid-season to harvesting late season of crop growth stage as the CWR is more than the ER, additional IR is needed to compensate ET losses in the decades 202130,2031-40 and 2041-50 i.e., 2.8\% less than that for BL condition and $14 \%$ and $26.8 \%$ more than that for $\mathrm{BL}$ condition respectively.

During rabi season, the rainfall obtained in the months is very less as compared to other season and hence the ER will also be less. The crop water requirements for Rabi crops are shown in table2.

Jowar (Rabi): The CWR for the crop is more for A1B scenario as compared to BL condition. For the decade 202130 , during middle of the development stage to harvesting season of the crop, and for decades 2031-40 and 2041-50, from initial to harvesting season of the crop, the CWR is more compared to ER. Therefore IR is needed to compensate ET losses in the decades 2021-30, 2031-40 and 2041-50 i.e., $2.1 \%$ less and 7.4\%, $1.3 \%$ more than that for BL condition respectively.

Maize (Rabi): The CWR for the crop is more for period 2031-40 and 2041-50 as compared to BL condition, but for period 2021-30 it is same as BL. For the decade 2021-30, 2031-40 and 2041-50, from initial to harvesting season of the crop, the CWR is more compared to ER. Therefore IR is needed to compensate ET losses in the three decades i.e., $2.7 \%$ and $1.1 \%$ less in case of period 2021-30 and 2041-50 and in case of period 2031-40, 2.6\% more than that for BL condition. 
Wheat (Rabi): The CWR for the crop is more for period 2031-40 and 2041-50 as compared to BL condition, but for period 2021-30 it is less than BL. For the decade 2021-30, during middle of the development stage to harvesting season of the crop, and for decades 2031-40 and 2041-50, from initial to harvesting season of the crop, the CWR is more compared to ER. Therefore IR is needed to compensate ET losses in the three decades i.e., $3.4 \%$ and $2.2 \%$ less in case of period 2021-30 and 2041-50 and in case of period 2031$40,4.2 \%$ more than that for BL condition.

For the perennial crop i.e., Sugarcane, the CWR is higher for A1B scenario compared to BL condition due to increase in minimum and maximum temperature than in BL. As the crop is a perennial one, the total ER will be less compared to total water requirement of the crop. Therefore IR is needed to compensate ET losses in all the three decades i.e., 9\%, $19.7 \%$ and $27.9 \%$ more than in BL condition respectively. The crop water requirement for Sugarcane is shown in Table3.

\section{CONCLUSIONS}

The reference evapotranspiration values are increased in the future period as compared to present condition due to increase in temperature. The crop water requirement for various crops is calculated and listed in table. The results shows that, for crops Groundnut, Cotton, Sugarcane, Jowar (rabi), Maize(rabi) and Wheat (rabi) there is an increase in CWR in the future scenario as compared to BL. Whereas for the remaining crops there is a little decrease in CWR.

Results and analysis concludes the climate change impacts on CWR of kharif and rabi crops. The study reveals that there is both rise and fall in CWR for future scenario when compared with base line condition.

The outcomes of this study is capable for policy makers and planners of water resources for future planning and helps to save water in satisfying crop water requirement. In order to meet the irrigation requirement for the increased population and the stress on greater production requirement per unit of agricultural land it is necessary to find ways to save water in the existing practice. The method presented in the thesis will be helpful in identifying the year in which effective rainfall is more and irrigation water requirement is low. Therefore, water saved due to the reduced water requirement of crop from any irrigation project can be used to extend irrigation facility to other fields. Thereby it helps to increase the gross crop production which contributes towards satisfying the food requirement of the country partially. Alternatively farmers may be taught to practice water conservation measures effectively and in addition they should be encouraged to use drip and sprinkler irrigation systems instead of other methods which require large quantity for irrigation.

\section{ACKNOWLEDGEMENT}

I am overwhelmed with rejoice to avail this rare opportunity to acknowledge Associate Prof. Nagaraj S Patil, dept. of water and land management, VTU Belagavi for his imperative suggestions and fruitful criticism and also to acknowledge IMD Bangalore, Agricultural dept. and Statistical dept., Belagavi for the provision of required information.

\section{REFERENCES}

[1]. Allen, R.G., Pereira, L.S., Raes, D., Smith, M., (1998). "Crop evapotranspiration: Guidelines for computing crop water requirements". FAO Irrigation and Drainage Paper 56, FAO, Rome, Italy.

[2]. Branislava Lalic, Maria Francia, Goran Jacimovic. (2013). "Assessment of climate change impact on crop water requirements in Serbia in 2030 using CROPWAT model".

ResearchGate (http://www.researchgate/publication/271841450), Conference paper -38 .

[3]. Doria, R., Madramootoo, C. A., and Mehdi, B. B., (2006). "Estimation of Future Crop Water Requirements for 2020 and 2050 Using CROPWAT", IEEE, 1-4244-0218-2/06.

[4]. Dr. Falguni Parekh, Kevin Pramod Chandra Prajapati., (2013). "Climate change impacts on crop water requirement for sukhi reservoir project". International journal of innovative research in science, engineering and technology (ISSN: 23199-8753), vol. 2, issue 9, pp:4685-4692.

[5]. Gladden L. A., (2014). "A Predictive Approach to Simulate Possible Impacts of Climate Change on the Agricultural Sector". Journal of Earth Science \& Climatic Change (ISSN:2157-7617), Volume 5, Issue 9, paper ID: 1000231,pp:1-7.

[6]. Jyun-Long Lee., Wen-Cheng Huang., (2014). "Impact of Climate Change on the Irrigation Water Requirement in Northern Taiwan". Water (www.mdpi.com/journal/water), ISSN:2073-4441, paper ID: 6113339, pp:3339-3361.

[7]. Mohan, S., Ramsundram, N., (2014). "Climate Change and its Impact on Irrigation Water Requirements on Temporal Scale". Journal of Irrigation \& Drainage Systems Engineering (ISSN:2168-9768), Volume 3, Issue 1, paper ID:1000118, pp:1-8.

[8]. Shakhawat Chowdhury., Muhammad Al-Zahrani., Abdullah Abbas., (2013). "Implications of climate change on crop water requirements in arid region: An example of Al-Jouf, Saudi Arabia". Journal of King Saud University - Engineering Sciences (http:/dx.doi.org/10.1016/j.jksues.2013.11.001), Volume 28, Issue 1, pp:21-30.

[9]. Sudip Kumar Chatterjee., Saon Banerjee., Mridul Bose., (2012). "Climate Change Impact on Crop Water Requirement in Ganga River Basin, West Bengal, India". Third International Conference on Biology, Environment and Chemistry IPCBEE, Volume 46, pp:17-20.

[10]. Ziad, A. Mimi., Sireen Abu Jamous., (2010). "Climate change and agricultural water demand: Impacts and adaptations". African Journal of Environmental Science and Technology (ISSN:1991-637), Volume 4, pp:183-191. 


\section{BIOGRAPHIES}

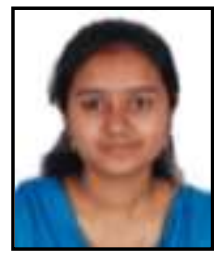

\section{Manasa H G}

M.Tech student,

Dept. of Water and land management,

Visvesvaraya technological university, Belagavi, India.

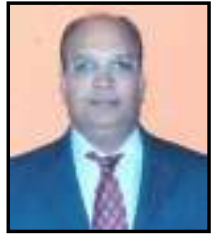

Dr. Anand V Shivapur: He is currently working as Professor and HOD of Water and Land Management dept., Centre for PG Studies, VTU, Belagavi. He has total experience of 31 years in teaching, administration and research. He has published more than 25 research papers in National as well as International journals. 60 papers in conf., seminar etc. He has guided $2 \mathrm{PhD}$ students and 6 scholars are pursuing research. His research areas are Watershed management, Hydrology, Use of RS and GIS for Irrigation and Watershed.

Table-1: Crop Water Requirement For Kharif Crops Under Bl and A1b Scenarios.

\begin{tabular}{|c|c|c|c|c|c|c|c|}
\hline \multicolumn{8}{|c|}{ JOWAR } \\
\hline \multirow{2}{*}{ PARAMETER } & \multirow{2}{*}{$\begin{array}{l}\text { BL } \\
\text { MCM/year }\end{array}$} & \multicolumn{2}{|c|}{ 2021-30 } & \multicolumn{2}{|c|}{$2031-40$} & \multicolumn{2}{|c|}{ 2041-50 } \\
\hline & & MCM/year & $\%$ & MCM/year & $\%$ & MCM/year & $\%$ \\
\hline $\mathbf{E T}_{\mathbf{C}}$ & 20.73 & 16.53 & -20.3 & 17.20 & -17.1 & 17.98 & -13.3 \\
\hline ER & 23.77 & 41.67 & 75.3 & 42.18 & 77.4 & 41.47 & 74.5 \\
\hline IR & 1.32 & 0.00 & -100 & 0.00 & -100 & 0.00 & -100 \\
\hline \multicolumn{8}{|c|}{ MAIZE } \\
\hline $\mathbf{E T}_{\mathbf{C}}$ & 23.21 & 19.21 & -17.2 & 20.06 & -13.6 & 21.07 & -9.2 \\
\hline ER & 23.70 & 40.04 & 68.9 & 40.44 & 70.6 & 39.89 & 68.3 \\
\hline IR & 3.89 & 0.00 & -100 & 0.20 & -95 & 0.99 & -74.7 \\
\hline \multicolumn{8}{|c|}{ GROUNDNUT } \\
\hline $\mathbf{E T}_{\mathbf{C}}$ & 27.20 & 26.68 & -1.9 & 28.10 & 3.3 & 30.37 & 11.6 \\
\hline ER & 24.26 & 33.50 & 38.1 & 32.71 & 34.8 & 33.10 & 36.4 \\
\hline IR & 6.85 & 8.58 & 25.2 & 10.30 & 50.3 & 12.27 & 79.1 \\
\hline \multicolumn{8}{|c|}{ SOYBEAN } \\
\hline $\mathbf{E T}_{\mathbf{C}}$ & 49.95 & 44.39 & -11.1 & 47.13 & -5.7 & 50.19 & 0.5 \\
\hline ER & 47.44 & 77.34 & 63.0 & 77.30 & 62.9 & 78.23 & 64.9 \\
\hline IR & 9.64 & 0.83 & -91.4 & 1.99 & -79.3 & 4.27 & -55.7 \\
\hline \multicolumn{8}{|c|}{ COTTON } \\
\hline $\mathbf{E T}_{\mathbf{C}}$ & 28.45 & 26.56 & -6.6 & 27.69 & -2.7 & 29.51 & 3.7 \\
\hline ER & 22.89 & 34.80 & 52.0 & 34.46 & 50.5 & 34.36 & 50.1 \\
\hline IR & 8.65 & 8.40 & -2.8 & 9.86 & 14.0 & 10.97 & 26.8 \\
\hline
\end{tabular}


Table-2: Crop Water Requirements for Rabi Crops Under Bl and A1b Scenarios.

\begin{tabular}{|c|c|c|c|c|c|c|c|}
\hline \multicolumn{8}{|c|}{ JOWAR } \\
\hline \multirow{2}{*}{ PARAMETER } & \multirow{2}{*}{$\begin{array}{l}\text { BL } \\
\text { MCM/year }\end{array}$} & \multicolumn{2}{|c|}{ 2021-30 } & \multicolumn{2}{|c|}{$2031-40$} & \multicolumn{2}{|c|}{ 2041-50 } \\
\hline & & MCM/year & $\%$ & MCM/year & $\%$ & MCM/year & $\%$ \\
\hline $\mathbf{E T}_{\mathbf{C}}$ & 24.52 & 24.54 & 0.1 & 24.83 & 1.3 & 25.28 & 3.1 \\
\hline ER & 7.02 & 5.59 & -20.4 & 3.92 & -44.2 & 5.51 & -21.5 \\
\hline IR & 19.69 & 19.29 & -2.1 & 21.15 & 7.4 & 19.94 & 1.3 \\
\hline \multicolumn{8}{|c|}{ MAIZE } \\
\hline $\mathbf{E T}_{\mathbf{C}}$ & 8.75 & 8.75 & 0.0 & 8.84 & 1.1 & 8.94 & 2.2 \\
\hline ER & 1.77 & 1.53 & -13.5 & 1.23 & $\begin{array}{c}- \\
30.3\end{array}$ & 1.57 & -11.4 \\
\hline IR & 7.48 & 7.28 & -2.7 & 7.68 & 2.6 & 7.40 & -1.1 \\
\hline \multicolumn{8}{|c|}{ WHEAT } \\
\hline $\mathbf{E T}_{\mathbf{C}}$ & 2.99 & 2.98 & -0.3 & 3.01 & 0.6 & 3.03 & 1.4 \\
\hline ER & 0.63 & 0.55 & -12.7 & 0.38 & $\begin{array}{c}- \\
39.9 \\
\end{array}$ & 0.56 & -11.4 \\
\hline IR & 2.54 & 2.45 & -3.4 & 2.65 & 4.2 & 2.48 & -2.2 \\
\hline
\end{tabular}

Table-3: Crop Water Requirements for Perennial Crop Under Bl and A1b Scenario.

\begin{tabular}{|l|c|c|c|c|c|c|c|}
\hline \multicolumn{8}{|c|}{ SUGARCANE } \\
\hline \multirow{2}{*}{ PARAMETER } & \multirow{2}{*}{$\begin{array}{l}\text { BL } \\
\text { MCM/year }\end{array}$} & \multicolumn{2}{|c|}{$\mathbf{2 0 2 1 - 3 0}$} & \multicolumn{2}{|c|}{$\mathbf{2 0 3 1 - 4 0}$} & \multicolumn{2}{c|}{$\mathbf{2 0 4 1 - 5 0}$} \\
\cline { 3 - 8 } & MCM/year & \% & MCM/year & $\%$ & MCM/year & $\%$ \\
\hline ET & 109.88 & 110.90 & 0.9 & 116.60 & 6.1 & 122.95 & 11.9 \\
\hline ER & 45.08 & 61.02 & 35.4 & 58.75 & 30.3 & 58.05 & 28.8 \\
\hline
\end{tabular}

